\title{
ESTAFILOCOCOS COAGULASE POSITIVOS EM FILÉS DE TILÁPIA (Oreochromis niloticus) COMERCIALIZADOS NO MERCADO MODELO NERIVAL ARAÚJO, CURRAIS NOVOS/RN
}

\author{
F. A. G. Rocha ${ }^{1}$, L. O. Araújo, K. S. Alves, L. Í. S. Dantas, R. P. Silva, M. F. F. Araújo \\ Instituto Federal do Rio Grande do Norte - Campus Currais Novos \\ angelo.gurgel@ifrn.edu.br ${ }^{1}$
}

Artigo submetido em janeiro/2013 e aceito em fevereiro/2013

\section{RESUMO}

O peixe está entre os produtos de origem animal mais susceptíveis à proliferação microbiana, devido ao $\mathrm{pH}$ próximo a neutralidade, à elevada Atividade de Água nos tecidos e à alta disponibilidade de nutrientes. A baixa qualidade sanitária da matéria-prima ou condições inadequadas de higiene em fases da cadeia produtiva podem introduzir microrganismos indesejados. $\mathrm{Na}$ Região Seridó do Rio Grande do Norte, o pescado e seus derivados têm ampla aceitação pelo consumidor. Objetivamos quantificar a presença de estafilococos coagulase positivos em filés de Tilápia (Oreochromis niloticus) comercializados no município citado. Foram analisadas 15 amostras obtidas no Mercado Modelo Nerival Araújo. Utilizou-se a Contagem Direta em Placa, com semeadura em superfície (ágar Manitol Salgado, $\left.35^{\circ} \mathrm{C} / 24-48 \mathrm{~h}\right)$. A confirmação bioquímica dos microrganismos detectados foi realizada através dos testes de atividade termonuclease e coagulase. Em $100 \%$ das amostras, foram detectadas populações de $S$. aureus, sendo que em $73,3 \%$ dos casos, acima do padrão estabelecido pela legislação vigente. As altas contagens verificadas evidenciam a inadequação sanitária do material analisado, denunciando as baixas condições de higiene em sua produção e comercialização.

PALAVRAS-CHAVE: qualidade, pescado, contaminação, higiene, Staphylococcus aureus.

\section{COAGULASE POSITIVE STAPHYLOCOCCI FILLETS IN TILAPIA (Oreochromis niloticus) SOLD IN THE MARKET NERIVAL ARAÚJO, CORRAIS NOVOS/RN}

\begin{abstract}
Among the animal products, fish is one of the most susceptible to microbial proliferation for its almost neutral $\mathrm{pH}$, high water activity in tissue, and high nutrient availability. Poor health conditions of the raw material or inappropriate hygiene during the manufacturing process may insert unwanted microorganisms. In Serido, South region of the State of Rio Grande do Norte, fish and its products are widely accepted by consumers. We aim to quantify the presence of coagulase-positive staphylococci in Nile tilapia steaks marketed in the referred region. An amount of 15 samples obtained from the market
\end{abstract}

KEY-WORDS: quality, fish, contamination, hygiene, Staphylococcus aureus. 


\section{ESTAFILOCOCOS COAGULASE POSITIVOS EM FILÉS DE TILÁPIA (Oreochromis niloticus) COMERCIALIZADOS NO MERCADO MODELO NERIVAL ARAÚJO, CURRAIS NOVOS/RN}

\section{INTRODUÇÃO}

Desde os primórdios da história, o pescado constitui recurso nutricional importante para a humanidade. $\mathrm{O}$ aumento populacional e a busca por alimentos mais saudáveis vêm acelerando $\mathrm{O}$ crescimento da demanda mundial pelo produto.

Apesar das suas vantagens em relação às demais fontes de proteína animal, o peixe é um dos alimentos mais suscetíveis à proliferação microbiana. Isto se deve a sua Atividade de Água elevada, alta biodisponibilidade de macro e micronutrientes, teor de gorduras insaturadas de fácil oxidação e pH próximo da neutralidade.

A presença de microbiota patogênica em pescado relaciona-se com a qualidade da água de onde este provém. De modo geral, existe uma relação direta entre a poluição ambiental e a detecção de espécies dos Gêneros Listeria, Salmonella e Staphylococcus.

Dentre as espécies do Gênero Staphylococcus, Staphylococcus aureus se destaca pela sua patogenicidade para o homem e animais. Coco Gram-positivo, mesófilo e anaeróbio facultativo, é responsável por surtos de intoxicação alimentar, decorrentes da formação de toxinas estafilocócicas no alimento consumido.

O pescado encontra ampla aceitação pelos consumidores na região Seridó do Rio Grande do Norte. A espécie mais consumida é a Tilápia (Oreochromis niloticus), comercializada in natura ou na forma de derivados, em especial filés congelados. No Mercado Modelo Nerival Araújo (Currais Novos, RN) os filés são produzidos, armazenados e expostos sob condições inadequadas do ponto de vista higiênico sanitário. Neste contexto, sua qualidade microbiológica é negativamente impactada, podendo resultar em danos à saúde do consumidor.

\section{FUNDAMENTAÇÃO TEÓRICA}

Desde os primórdios da História, os peixes constituem alimento para a humanidade. Ao longo do tempo, a atividade pesqueira tornou-se promotora de benefícios econômicos e sociais, bem como importante fonte de divisas para os países produtores. $O$ aumento populacional e a busca por alimentos mais saudáveis vêm acelerando o crescimento da demanda mundial pelo produto. Em alguns países da Europa e Ásia, o pescado constitui a fonte preferencial de proteína animal, de alta qualidade, para a população (LIRA et al., 2001; SOARES et al., 2012).

No período 2004 a 2009, a produção mundial de pescado sofreu incremento de $13 \%$ em comparação ao total acumulado anteriormente. Atualmente, o produto disponível no mercado é obtido através da atividade pesqueira e aquícola, responsáveis pela produção global de 155,8 milhões de toneladas em 2007 e 159,2 milhões de toneladas em 2008. Neste contexto internacional, a participação brasileira é tímida, com produção equivalente a $0,69 \%$ (1,7 milhões de toneladas) em 2007 e 0,73\% (1,18 milhões de toneladas ) em 2008, ano no qual passa a ocupar a $21^{\text {a }}$ posição no ranking mundial de produção de pescado (BRASIL, 2010; SIDONIO et al., 2012).

Em nosso país, a piscicultura baseia-se principalmente no cultivo de tilápias, carpas, tambaquis, tambacus e Pacus. A tilápia é a espécie mais produzida, atingindo em 2009 o total de 
132.957 toneladas, equivalente a $39 \%$ do total de pescado oriundo da piscicultura continental. Espécie introduzida, originária da África, a Tilápia do Nilo (Oreochromis niloticus) pode ser encontrada em quase todo o território nacional, excetuando-se as bacias dos rios Amazonas e Paraguai, onde o seu cultivo não é permitido pela legislação ambiental em vigor (ATYAH et al., 2010; BRASIL, 2010).

Apesar das suas vantagens em relação às demais fontes de proteína animal, o peixe é um dos alimentos mais suscetíveis à proliferação microbiana. Isto se deve a sua Atividade de Água elevada, alta biodisponibilidade de macro e micronutrientes, teor de gorduras insaturadas de fácil oxidação e pH próximo da neutralidade (FRANCO; LANDGRAF, 2008). Considerando-se que em peixes saudáveis os tecidos internos são estéreis, os microrganismos presentes naturalmente encontram-se principalmente no muco que os reveste externamente, brânquias e intestinos (JAY, 2005).

Os Gêneros Pseudomonas, Moraxella, Shewanella, Flavobacterium, Vibrio, Micrococcus, Aeromonas, Bacillus e Plesiomonas são componentes relevantes na microbiota presente em pescados de águas tropicais e sub-tropicais. A microbiota de peixes de água salgada tende a ser predominantemente Gram-negativa, ao contrário da presente em peixes de água doce e de climas mais quentes, predominantemente composta por bactérias Gram positivas mesofílicas (FRANCO; LANDGRAF, 2008; JAY, 2005).

De modo geral, quanto mais poluído o ambiente aquático, maior a diversidade da microbiota que pode ser encontrada nos peixes, incluindo espécies patogênicas para humanos. Dentre estas, Listeria spp., Salmonella spp. e Staphylococcus spp. têm sido isoladas a partir de pescado disponível ao consumidor (BOARI et al., 2008; DASKALOV, 2006; DESTRO, 2000; JAY, 2005; MEDEIROS et al., 2010; NEDOLUHA; WESTHOOF, 1997).

O Gênero Staphylococcus (Família Micrococcaceae) é composto por 19 espécies de cocos Gram positivos, predominantemente anaeróbios facultativos e mesófilos, capazes de crescer entre $7^{\circ} \mathrm{C}$ a $47,8^{\circ} \mathrm{C}$. Dentre as espécies que compõem o Gênero, as coagulase positivas são apontadas como patogênicas para humanos. Nesta categoria enquadram-se S. hyicus, S. intermedius e $S$. aureus. Esta última espécie tem sido implicada com frequência como agente causal em surtos de doenças estafilocócicas. Adicionalmente, a sua detecção em certos níveis é utilizada pela indústria de alimentos como bioindicadora da qualidade sanitária de um produto (FRANCO; LANDGRAF, 2008).

No município de Currais Novos/RN, o pescado encontra ampla aceitação popular. Seguindo a tendência nacional, a espécie de cultivo mais frequente em açudes e barragens das regiões Seridó Oriental e Seridó Ocidental é a Tilápia (Oreochromis niloticus). O produto é disponibilizado ao consumidor na feira livre e no mercado do município, in natura ou na forma de filés congelados, produzidos artesanalmente. No mercado municipal, o produto é processado, armazenado e exposto sob condições inadequadas, o que pode afetar de forma negativa a sua qualidade microbiológica e a saúde do consumidor (MEDEIROS et al., 2010).

\section{OBJETIVO}

O presente trabalho teve como objetivo geral quantificar a presença de $S$. aureus em filés de tilápia comercializados no Mercado Modelo Nerival Araújo (Currais Novos, RN), caracterizando-as perante a legislação pertinente como adequadas ou não ao consumo humano. 
De forma específica, objetivamos observar e registrar as condições higiênico-sanitárias e práticas presentes na comercialização do produto na área citada.

\section{MATERIAL E MÉTODOS}

\section{Área estudada}

As amostras foram coletadas no mercado Modelo Nerival Júnior, em Currais Novos, Rio Grande do Norte. O município situa-se na mesorregião Central Potiguar e microrregião Seridó Oriental sob coordenadas $6^{\circ} 15^{\prime} 39,6^{\prime \prime}$ de latitude Sul e $36^{\circ} 30^{\prime} 54^{\prime \prime}$ de longitude Oeste (figura 1). Sua distância da capital do estado, Natal, é de aproximadamente 192 Km (BRASIL, 2005).

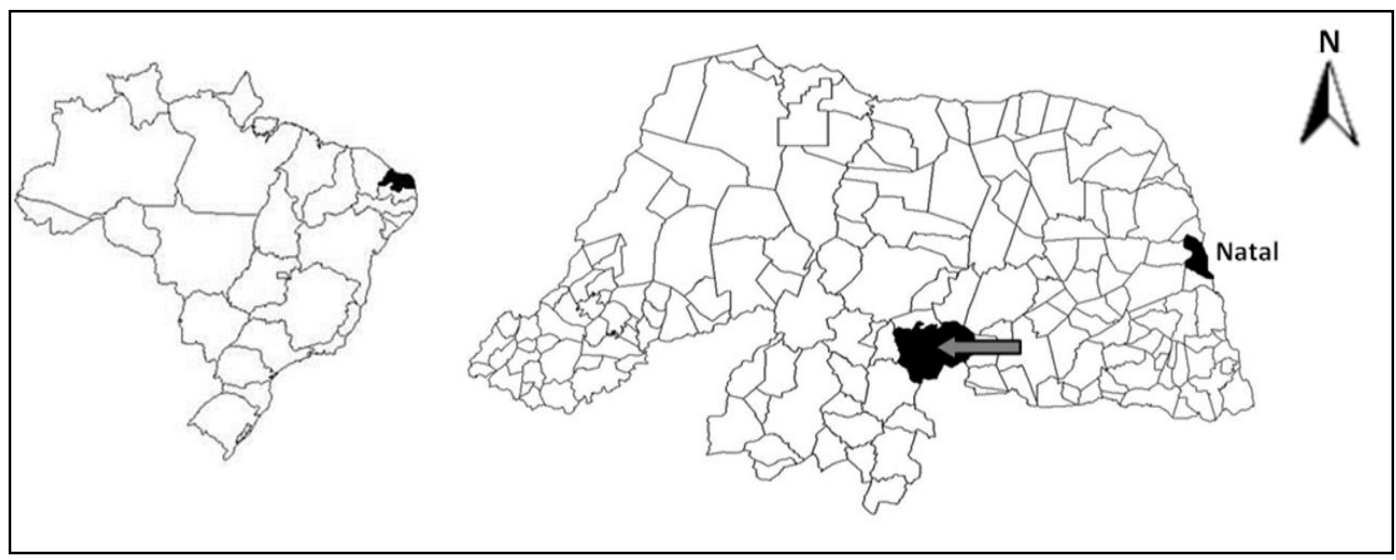

Figura 1 - Localização do Estado do Rio Grande do Norte e do município de Currais Novos/RN, indicado pela seta (BRASIL, 2012).

\section{Observações em campo}

Como elemento norteador das observações, utilizou-se a Portaria SVS/MS n 326 de 30 de julho de 1997 (BRASIL, 1997). Durante as visitas, foram observados e registrados aspectos relacionados à: estrutura física do local; rotinas de higiene geral e pessoal; presença de resíduos sólidos; uso de EPI; utensílios e equipamentos adequados à atividade; condições de exposição, armazenamento dos produtos; práticas de manipulação e processamento do pescado. Quando necessário, recorreu-se ao registro fotográfico.

\section{Amostras}

Utilizou-se um plano de amostragem de duas classes, no qual a unidade amostral é categorizada como aceitável ou não para consumo humano, admitindo-se $n=15$. Como legislação de referência, foram adotados os limites estabelecidos pela Agencia Nacional de Vigilância Sanitária para a presença de estafilococos coagulase positivos em pescado in natura, resfriado ou congelado, não consumidos crus (BRASIL, 2001).

As amostras coletadas foram acondicionadas em recipientes estéreis, que por sua vez, foram depositadas em caixa isotérmica. O material foi conduzido ao Laboratório de Microbiologia de Alimentos/Biologia Molecular (MicroBio) do IFRN Campus Currais Novos, onde foi analisado.

\section{Análises microbiológicas}


A partir das amostras, foram realizadas diluições decimais seriadas em solução salina peptonada, da ordem de $10^{-1}$ a $10^{-3}$. A partir destas, alíquotas de $0,1 \mathrm{~mL}$ foram individualmente semeadas (spread plate) em duplicatas de placas de petri contendo cerca de $20 \mathrm{~mL}$ de ágar manitol salgado. Após o processo, as placas foram incubadas em posição invertida em estufa bacteriológica a $35 \pm 2{ }^{\circ} \mathrm{C} / 24-48 \mathrm{~h}$. Foram consideradas presuntivas de $S$. aureus as colônias circulares, pequenas, convexas, com coloração amarela, derivada da produção de ácido resultante da metabolização do manitol presente do meio (HAJDENWURCEL, 2004; LEBOFFE; PIERCE, 2005). Colônias presuntivas de $S$. aureus foram inoculadas em tubos de ensaio contendo $5 \mathrm{~mL}$ de ágar nutriente inclinado e depositadas na bacterioteca do IFRN, Campus Currais Novos, para posterior confirmação bioquímica, realizada através dos testes das Atividades Termonuclease e Coagulase em lâmina.

Os resultados obtidos foram expressos em Unidades Formadoras de Colônia por grama (UFC/g) e contrastados com as orientações contidas na RDC N. 012, de 2 de Janeiro de 2001, da Agência Nacional de Vigilância Sanitária (BRASIL, 2001).

\section{RESULTADOS E DISCUSSÃO}

Foi analisado um total de 15 amostras, sendo a presença de $S$. aureus confirmada em $100 \%$ dos casos. A densidade média observada do microrganismo nas amostras correspondeu a $9,6 \times 10^{3} \mathrm{UFC} / \mathrm{g}$. As densidades mínima e máxima detectadas foram equivalentes a $2,0 \times 10^{2} \mathrm{UFC} / \mathrm{g}$ e $4,1 \times 10^{4} \mathrm{UFC} / \mathrm{g}$, respectivamente.

Tabela 1 - Classificação das amostras de filés de tilápia analisadas, perante os limites estabelecidos pela ANVISA para a presença de estafilococos coagulase positivos em pescado congelado.

\begin{tabular}{ccccccc}
\hline $\begin{array}{c}\text { Total de } \\
\text { amostras } \\
\text { analisadas }\end{array}$ & $\begin{array}{c}\text { Atendem ao } \\
\text { padrão }\end{array}$ & $\begin{array}{c}\text { Não atendem ao } \\
\text { padrão }\end{array}$ & \multicolumn{2}{c}{$\begin{array}{c}\text { Total de amostras } \\
\text { contaminadas por } \\
\text { S. aureus }\end{array}$} \\
\cline { 2 - 7 } & Amostras & $\%$ & Amostras & $\%$ & Amostras & $\%$ \\
\hline 15 & 4 & 26,7 & 11 & 73,3 & 15 & 100 \\
\hline
\end{tabular}

Conforme a tabela 1, em 73,3\% dos casos detectou-se densidades superiores a $10^{3} \mathrm{UFC} / \mathrm{g}$, limite legal estabelecido na legislação de referência adotada. Neste contexto, tais amostras foram consideradas como inadequadas ao consumo humano.

A detecção do microrganismo alvo em $100 \%$ das amostras é superior ao percentual de $35 \%$ encontrado por Atyah et al. (2010) em estudo desenvolvido na Malásia. Boari et al. (2008) em análise da cadeia produtiva de filés de Tilápia na cidade de Lavras/MG, apontou a presença de S. aureus em 30\% das amostras analisadas. Por sua vez, Soares et al. (2012), relatam a não detecção de $S$. aureus em filés de tilápia conservados em gelo, provenientes do município de Apodi (RN).

Altas densidades de $S$. aureus em alimentos constituem risco à saúde humana, dado o seu potencial toxigênico. As toxinas estafilocócicas são higroscópicas solubilizando-se com facilidade em água e soluções salinas, o que permite a sua rápida difusão no alimento contaminado. Tais toxinas são termorresistentes e quimiorresistentes, não sendo afetadas pelo cozimento do alimento, nem pela exposição posterior às enzimas digestivas presentes no trato gastrintestinal humano. Adicionalmente, são capazes de provocar intoxicação em humanos, mesmo quando presentes em concentrações da ordem de 0,015 $\mu \mathrm{g} / \mathrm{kg}$ (FRANCO; LANDGRAF, 2008). 


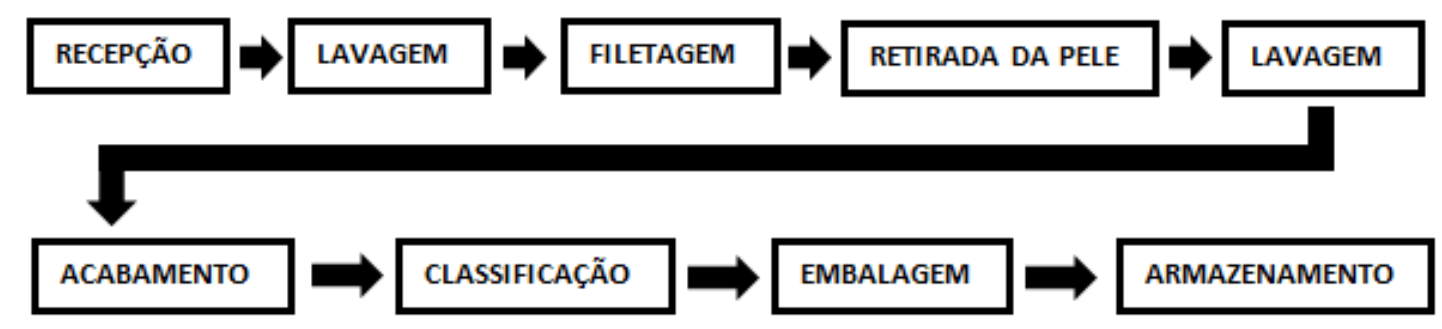

Figura 2 - Fluxograma das etapas relacionadas à produção do filé de tilápia. Adaptado a partir de Bartolomeu et al. (2011).

A presença de $S$. aureus em alimentos é bioindicadora de sanitização deficiente em uma ou mais etapas da sua cadeia produtiva (FRANCO; LANDGRAF, 2008). As etapas envolvidas na produção dos filés de tilápia (figura 2), caso realizadas em condições de higiene inadequadas, podem favorecer a contaminação do pescado por este microrganismo, tendo em mente a qualidade sanitária da manipulação e dos insumos utilizados em seu processamento.

Os resultados das análises são compatíveis com as condições presentes na comercialização do produto. Observou-se que todas as etapas descritas por Bartolomeu et al. (2011) - excetuando-se a excisão da pele, mantida no produto analisado - ocorriam no mesmo espaço onde este era armazenado, exposto e comercializado (figuras 3 e 4).

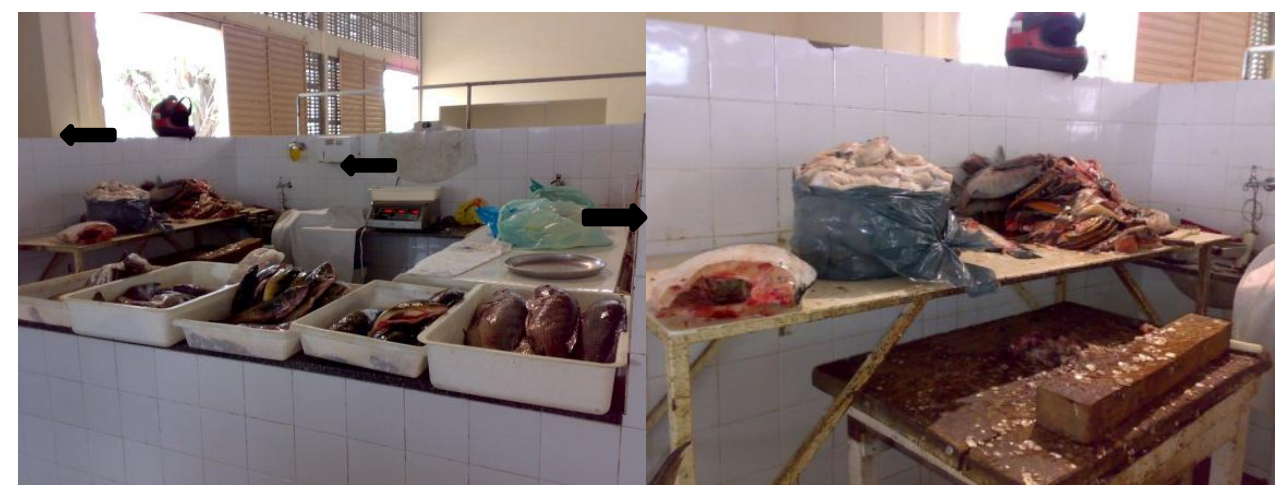

Figura 3 e 4 - Respectivamente: visão geral de um dos pontos de comercialização de pescado. Setas indicam tecido de algodão utilizado na limpeza das bancadas e capacete imediatamente acima da área destinada ao preparo dos filés; Detalhe da área destinada à produção dos filés de tilápia. Seta indica saco plástico no qual o produto era mantido em temperatura ambiente até o acondicionamento final em alíquotas de $1 \mathrm{Kg}$.

Em todas as observações, a manipulação do produto e o recebimento de dinheiro eram realizados por uma mesma pessoa, sem a adequada higienização, contrariando as orientações pertinentes. É fato conhecido que S. aureus, dentre outros microrganismos, pode ser veiculado através de cédulas de dinheiro (SOUZA et al. 2006). Adicionalmente, não se observou o uso de luvas por parte dos manipuladores, o que pode ter contribuído, de forma significativa, para a presença do microrganismo alvo nas amostras: Muratori et al. (2007) em estudo voltado à deteç̧ão de $S$. aureus e Escherichia coli nas mãos de manipuladores, em quatro estações de piscicultura no Piauí, relataram a detecção de $S$. aureus em até $93,8 \%$ dos casos.

As superfícies de trabalho nos pontos de comercialização visitados eram higienizadas com uso de panos de limpeza confeccionados em algodão, lavados e secos nas próprias áreas de 
comercialização (figura 3). Durante as coletas, não foram observados procedimentos de lavagem e desinfecção adequados nos panos utilizados na limpeza das superfícies. Embora sejam reconhecidas fontes de contaminação cruzada, os panos de limpeza são extensivamente utilizados nos serviços de alimentação. Bartz (2008) detectou neste tipo de material, populações de coliformes de até $10^{7} \mathrm{UFC} / \mathrm{cm}^{2}$ e no caso de $S$. aureus, até $2,8 \times 10^{6} \mathrm{UFC} / \mathrm{cm}^{2}$. Em experimento de dispersão bacteriana, o mesmo autor determinou que panos de limpeza experimentalmente contaminados com cargas microbianas correspondentes a $10^{4} \mathrm{UFC} / \mathrm{cm}^{2}$, podem transferir aproximadamente $10^{2} \mathrm{UFC} / \mathrm{cm}^{2}$ de bactérias para superfícies de aço inox.

Outras inadequações de cunho higiênico-sanitárias observadas nos pontos de comercialização foram: presença de objetos estranhos ao processamento do pescado; acesso livre de insetos e poeiras aos filés durante o seu preparo; acúmulo de restos de tilápia e outras espécies (escamas, sangue, tecidos...) na área de trabalho; uso de madeira no revestimento das superfícies onde o processamento ocorria; manutenção do pescado em temperatura ambiente ao longo de todas as etapas do fluxo de processamento. Este último aspecto havia sido observado por Medeiros et al. (2010) em estudo desenvolvido no mesmo mercado. Os autores relataram que parte do produto embalado era exposto aos visitantes à temperatura ambiente. Embora previamente congelado, ao longo do período matutino, o produto sofria variações positivas de temperatura, facilitando a proliferação microbiana.

\section{CONSIDERAÇÕES FINAIS}

Das 15 amostras analisadas 73,3\% foram consideradas inadequadas ao consumo humano, representando risco à saúde do consumidor. A inobservância dos princípios de Boas Práticas por parte dos comerciantes favoreceu a contaminação e a posterior proliferação microbiana.

Recomendamos a implantação de um programa de monitoramento contínuo da qualidade do pescado disponível no Mercado Modelo Nerival Araújo e o desenvolvimento de ações voltadas à implantação de Boas Práticas para os comerciantes envolvidos na cadeia produtiva da Tilápia no município de Currais Novos/RN.

\section{REFERÊNCIAS BIBLIOGRÁFICAS}

1. ATYAH, M. A. S.; ZAMRI-SAAD, M ; SITI-ZAHRAH. First report of methicillin-resistant Staphylococcus aureus from cage-cultured tilapia (Oreochromis niloticus). Veterinary microbiology, v. 144, 502-504, 2010.

2. BARTOlOMEU, D. A. F. S.; DAlLABONA, B. R.; MACEDO, R. E. F.; KIRSCHNICK, P. G. Contaminação microbiológica durante as etapas de processamento de filé de tilápia (Oreochromis niloticus). Archives of veterinary Science. v. 16, n.1, 21-30, 2011.

3. BARTZ, S. Contaminação microbiológica e avaliação de métodos de higienização de panos de limpeza utilizados em serviços de alimentação. Dissertação. Curso de Nutrição. Porto Alegre: Universidade Federal do Rio Grande do Sul, 2008.

4. BOARI, C. A.; PEREIRA, G. I.; VALERIANO, C.; Silva, B. C.; MORAIS, V. M.; FIGUEIREDO, H. C. P.; PICOLLI, R. H. Bacterial ecology of tilapia fresh fillets and some factors that can influence their microbial quality. Ciência e Tecnologia de Alimentos. v. 28, n. 4, p. 863-867, 2008.

5. BRASIL. Ministério da Saúde. Portaria SVS/MS n 326 de 30 de julho de 1997. Aprova o Regulamento Técnico; "Condições Higiênicos-Sanitárias e de Boas Práticas de Fabricação para Estabelecimentos Produtores/Industrializadores de Alimentos". Diário Oficial da República Federativa do Brasil, Poder Executivo, Brasília, DF, 01 de agosto de 1997. 
6. BRASIL. MINISTERIO DA SAÚDE. ANVISA. RDC 12, de 2 de janeiro de 2001. Aprova o regulamento técnico sobre padrões microbiológicos para alimentos. Diário Oficial da União. Poder Executivo. Brasília, DF, janeiro de 2001.

7. BRASIL. MINISTÉRIO DAS MINAS E ENERGIA. Projeto de fontes de abastecimento por água subterrânea no Estado do Rio Grande do Norte: Diagnóstico do Município de Currais Novos. Brasília, DF, 2005.

8. BRASIL. Instituto Brasileiro de Geografia e Estatística - IBGE. Escolares - Mapas. Base de dados. 2012. Disponível em: <http://mapas.ibge.gov.br". Acesso em 16 fev 2012.

9. BRASIL. Ministério da Pesca e Aquicultura. Boletim Estatístico da Pesca e Aquicultura: Brasil 2008-2009. Ministério da Pesca e Aquicultura, Brasília, DF, 2010.

10. DASKALOV, H. The importance of Aeromonas hydrophila in food safety. Food Control. v. 17, n. 6, 474-483, 2006.

11. DESTRO, m. t. Incidence and significance of Listeria in fish and fish products from Latin America. International Journal of Food Microbiology. v. 62, n. 3, 191-196, 2000.

12. FRANCO, Bernadette D. G. de; LANDGRAFF, Mariza. Microbiologia dos alimentos. São Paulo: Atheneu, 2008.

13. HAJDENWURCEL, J. R. Atlas de microbiologia de alimentos. v.1. São Paulo: Fonte Comunicação e Editora, 2004.

14. JAY, J. M. Microbiologia de Alimentos. Porto Alegre: Artmed. 6 ed, 2005.

15. LEBOFFE, M. J.; PIERCE, B. E. A photographic atlas for the microbiology laboratory. Englewood: Morton Publishing Company. 3 ed, 2005.

16. LIRA, G.M. et al. Avaliação da qualidade de peixes comercializados na cidade de Maceió - Al. Revista Higiene Alimentar, v.15, n.84, p.67-74, maio 2001.

17. MEDEIROS, S. P. A.; ROCHA, Francisco Angelo Gurgel da; MONTE, R. S.; NÓBREGA, W. K. D.; SILVA, R. P. Presença de Salmonella sp. em filés de Tilápia-do-Nilo (Oreochromis niloticus) congelados comercializados no mercado central de Currais Novos, RN. In: XXII Congresso Brasileiro de Ciência e Tecnologia de Alimentos - CBCTA, 2010, Salvador - BA. Ciência e Tecnologia de Alimentos: potencialidades, desafios e inovação, 2010.

18. MURATORI, M. C. S.; COUTO FILHO, C. C. C.; ARARIPE, M. N. B. A.; LOPES, J. B.; COSTA, A. P. R. Escherichia coli e Staphylococcus aureus em manipuladores da piscicultura. Revista Científica de Produção Animal. v. 9, n. 2, 120-126, 2007.

19. NEDOLUHA, P. C.; WESTHOOF, D. Microbiology on striped bass grown in three aquaculture systems. Food microbiology. v. 14, n. 3, p. 255-264, 1997.

20. SOARES, K. M. P. S.; GONÇALVES, A. A.; SOUZA, L. B .; SILVA, J. B. A. Pesquisa de Staphylococcus aureus em tilápia do Nilo (Oreochromnis niloticus) armazenadas em gelo. Acta veterinária Brasilica. v. 6, n.3, 239-242, 2012.

21. SIDONIO, L.; CAVALCANTI, I.; CAPANEMA, L.; MORCH, R.; MAGALHÃES, G.; LIMA, J.; BURN S, V.; ALVES JÚNIOR, A. J.; MUNGIOLI, R. Panorama da aquicultura no Brasil: desafios e oportunidades. BNDES Setorial - Agroindústria. n . 35, p. 421-463, 2012.

22. SOUZA, A. C.; OLIVEIRA, G. E. M.; OGAWA, W. N. POLLETO, K. Q. Microrganismos encontrados em dinheiro brasileiro coletado em feira-livre. NewsLab. ed. 77, 2006. 